\title{
BMJ Open Quality Development of a combined paediatric emergency department and observation unit
}

\author{
Czer Anthoney Enriquez Lim (D) , ${ }^{1,2}$ Julie Oh, ${ }^{1,2}$ Erick Eiting, ${ }^{1}$ Catherine Coughlin, ${ }^{1}$ \\ Yvette Calderon, ${ }^{1}$ Barbara Barnett ${ }^{1}$
}

To cite: Lim CAE, Oh J, Eiting $\mathrm{E}$, et al. Development of a combined paediatric emergency department and observation unit. BMJ Open Quality 2020;9:e000688. doi:10.1136/ bmjoq-2019-000688

Received 7 April 2019 Revised 23 July 2019 Accepted 17 December 2019

Check for updates

(c) Author(s) (or their employer(s)) 2020. Re-use permitted under CC BY-NC. No commercial re-use. See rights and permissions. Published by BMJ.

${ }^{1}$ Department of Emergency Medicine, Mount Sinai Beth Israel, Icahn School of Medicine at Mount Sinai, New York, New York, USA

${ }^{2}$ Department of Pediatrics, Mount Sinai Beth Israel, Icahn School of Medicine at Mount Sinai, New York, New York, USA

Correspondence to Dr Czer Anthoney Enriquez Lim; czeranthoney.lim@mountsinai. org

\section{ABSTRACT}

Background Recent trends towards more cost-efficient and patient-centred treatment are converging to provide opportunities to improve the care of children. Observation units are hospital areas dedicated to the ongoing evaluation and management of patients for a brief period of time for well-defined conditions. We describe the implementation of a paediatric observation unit (POU) adjacent to a paediatric emergency department (PED) in an urban, academic, community hospital.

Methods Staffing models were designed to provide paediatric services to patients in both the PED and POU. Admission criteria, workflow and transfer guidelines were developed. Quality improvement initiatives were undertaken and evaluated. Unit throughput, patient outcomes and patient satisfaction data were collected and analysed.

Results Over a 2-year period, there were 24038 patient visits to the PED. Of these, 1215 (5.1\%) patients required admission. Seven hundred and seventy-seven (64.0\%) of these children were admitted to the POU. One hundred and nineteen $(15.3 \%)$ of these patients were subsequently converted to inpatient hospitalisation. The average length of stay (LOS) was 25.7 hours in 2017 and 26.5 hours in 2018. Ten patients returned to the PED within 72 hours of discharge from the POU and four were readmitted. Patient satisfaction scores regarding 'likelihood to recommend' improved from the 36th to the 92nd percentile rank over a 1-year period. Close monitoring of patient outcomes allowed for the adjustment of admission guidelines, increased unit census and optimised utilisation.

Conclusion A combined PED-POU has been successful at our institution in meeting benchmark goals set for LOS and conversion rates. In addition, quality improvement interventions increased patient census and improved patient satisfaction scores while reducing the inpatient burden on the referring children's hospital.

\section{INTRODUCTION}

\section{Statement of the problem and key literature}

Recent trends towards more cost-efficient and patient-centred care and changes in the fields of paediatric emergency and hospital medicine are converging to provide opportunities for innovation in the care of children requiring hospitalisation. ${ }^{12}$ With the exception of the highest volume referral centres, most paediatric inpatient units do not generate net revenue and net losses are offset by gains from other revenue-generating areas of the hospital or department. ${ }^{3-5}$ The majority of general paediatric admissions are for respiratory and gastroenteritis-related illnesses, ${ }^{6-11}$ and the diagnostic-related group reimbursements for these low-acuity illnesses are relatively low. In contrast, the overhead costs to supply and staff a paediatric inpatient unit, which include specialty training of nurses, provision of paediatric-specific supplies and equipment, and extra accommodations such as child life services, are relatively costly. Additionally, as the highest rates of childhood hospitalisations occur during the winter months, during the rest of the year, paediatric inpatient units tend to have a low census.

Faced with the challenge of making hospital systems more cost-efficient, many have focused on curtailing paediatric inpatient services as a cost-cutting measure resulting in an overall decrease in the number of inpatient paediatric beds nationwide. ${ }^{6} \quad 12$ Instead, children requiring inpatient hospitalisation are either admitted to mixed age medical-surgical units or transferred to other hospitals with paediatric inpatient units. ${ }^{13}$ Although medical-surgical units and emergency departments (ED) may be effective in the management of adults, they often do not have adequate equipment and resources to support children and their families, ${ }^{14} 15$ such as paediatric nursing, child life, educational spaces and accommodations for family to remain at bedside 24 hours a day.

Utilisation of tertiary and quaternary care children's hospitals for paediatric subspecialty care in areas of congenital cardiac disease, oncology and transplant medicine has shown significant benefits and improved outcomes. ${ }^{16-20}$ While these hospitals were designed as paediatric subspecialty referral centres for large areas, the transfer of general paediatric admissions that were previously managed at smaller community hospitals has strained the capacity of those centralised 
systems. ${ }^{21} 22$ This inpatient overcrowding reverberates through the rest of the hospital, delaying the transfer of patients from critical care, postsurgical and emergency units, and hinders the ability of the hospital to continue to accept patients from referral centres. ${ }^{23-26}$ Preventing the need to transfer patients with mild to moderate conditions to a children's hospital can thus reduce inpatient overcrowding at the receiving facility.

The practices of paediatric emergency, hospital medicine and outpatient care are also evolving towards shorter hospitalisations coupled with outpatient management. ${ }^{27-30}$ Increasingly more paediatric surgical procedures are being conducted in ambulatory care centres. ${ }^{3132}$ Advances in the treatment of acute gastroenteritis, croup, bronchiolitis and febrile infants have resulted in a decreased need for hospitalisation of these patients. ${ }^{33-36}$ While creating a larger population of high-turnover patients, these changes in the management of common paediatric conditions create an opportunity to develop new systems for the care of these children requiring brief hospitalisations. ${ }^{37-39}$

Observation units are hospital areas dedicated to ongoing evaluation and management of patients, usually for a well-defined, brief period of time. ${ }^{40}$ A paediatric observation unit (POU) provides the ability to cohort children with minor illnesses traditionally requiring admission, therefore reserving inpatient beds for children with more severe illnesses. ${ }^{35}$ Scribano and colleagues ${ }^{41}$ report that over one-third of admissions from the paediatric emergency department (PED) can be cared for in observation units. After the opening of an observation unit in one centre, over half of asthma admissions were redirected from traditional inpatient settings. ${ }^{42}$ The average length of stay (LOS) in observation units ranged from 12 to 35 hours for asthma and 9 to 18 hours for dehydration. $^{2}$ In a study of children with asthma admitted to an inpatient unit by McConnochie and colleagues, ${ }^{43} 54 \%$ of patients met discharge requirements 8 hours after admission to an inpatient setting, and up to $74 \%$ of patients could have avoided inpatient hospitalisation altogether. Several studies have reported the financial benefit of observation treatment for asthma and dehydration, mostly due to lower charges for observation level versus traditional hospitalisation. ${ }^{44} 45$

The majority of POUs are located in tertiary care children's hospitals. ${ }^{9}$ A recent national survey by Macy and colleagues identified only three hospitals with observation beds that did not have inpatient paediatric units. ${ }^{46}$ There is an emerging need for alternative methods to care for children with brief illnesses. The development of POUs in hospitals without inpatient paediatric resources may present a resource-optimising solution that preserves the need for family-centred care.

\section{Specific aims}

Healthcare systems are currently faced with the challenge of continuing to provide patient-centred care in a more cost-efficient manner. We present the development of paediatric observation services for healthcare systems investigating sustainable models in community hospital settings. We designed and implemented a POU adjacent to an existing PED in an urban, academic, community hospital without inpatient paediatric services. We measured throughput metrics and patient-centred outcome data including patient volume, LOS, case mix, conversion rate and patient satisfaction scores. We also conducted specific quality improvement cycles to increase patient volume and optimise POU utilisation. Over the first 2 years of operation, our primary aim was to meet benchmarks set to limit LOS to less than 48 hours and maintain a $15 \%$ conversion rate.

\section{METHODS \\ Context}

At our urban, academic, community hospital, the PED is a self-enclosed unit with approximately 12000 annual visits and a $4.5 \%$ admission rate. Staffing is provided $24 / 7$ by physicians with paediatric emergency medicine (PEM) training. The development of a POU was done in response to the consolidation of paediatric inpatient services into a distant tertiary care children's hospital and the closure of the paediatric inpatient unit at our community hospital.

\section{Interventions}

Resource sharing strategy: unit design and staffing

There are various models on which observation units are structured and staffed, and the option chosen depends on balancing factors such as the needs and resources of the hospital with the availability of personnel, space and capital budget. We created a combined PED-POU by building a five-bed observation unit within existing space adjacent to the PED. Due to its close proximity to the PED, a minimum amount of capital investment was necessary to create the infrastructure needed to meet patient care, life safety and state regulatory requirements in the POU.

The clinical needs of our PED and POU were amenable to a combined staffing model. The PED requires 24/7 Pediatric Emergency Medicine (PEM) attending coverage, and during times of day with the highest patient arrivals, a second PEM attending was scheduled. Due to the expected rapid patient turnover in the POU, a paediatric hospitalist was employed to provide observation unit coverage for 16 hours a day. In addition to managing patients in the POU, the hospitalist would also see patients in the PED, which eliminated the need for the second PEM attending during high-volume periods. Prior to the development of the PED-POU, ancillary staffing was shared with the adult ED. The combined unit created the volume and patient care needs to provide dedicated paediatric nursing, child life and respiratory therapy services to the PED-POU.

At times of low census in the observation unit or surge events in the PED, the observation unit staff assisted with the care of patients in the PED, and unoccupied observation beds were used as overflow PED beds. If patients 
clinically decompensated in the POU, the PED staff provided critical care services to help stabilise the patient and arranged transfer to a higher level of care. Additionally, this also allowed ancillary staff such as child life, which was not regularly available beforehand, to provide daily services to families in both units.

\section{Patient transfer mechanisms}

Transfer protocols were developed to ensure the safe and efficient transfer of children between facilities within the health system. For patients with emergent and lifethreatening conditions, rapid transport protocols were developed that initiated parallel processes of provider handoff and mobilisation of ambulance, critical care and operative services.

\section{Clinical care guidelines and target conversion rate}

A multidisciplinary task force consisting of physicians and nurses from the PED and POU collaboratively determined the initial admission and management guidelines that would optimise throughput within the two units. The case mix and conversion rate are determined by the severity and complexity of illnesses, the capabilities of the facility, subspecialty presence and the availability of higher level care for patients that clinically deteriorate. Among adult observation units, a target conversion rate of 20\%-30\% balances the need for efficient throughput in the ED with the potential loss of revenue to the hospital. ${ }^{2}$ Our target conversion rate was set at $15 \%$ to accommodate the needs of families and limit conversions that would require ambulance transfer to inpatient units at an off-site children's hospital.

\section{Quality improvement cycles}

We concurrently engaged in ongoing quality improvement activities to increase the POU volume by minimising conversions and expanding available services. Review of patient dispositions from the PED and their clinical course in the POU or inpatient units allowed for the ongoing modification of admission and treatment guidelines. This identified groups that might benefit from observation services and optimised POU utilisation.

\section{Adjustments to admission guidelines}

Physician discretion allowed children to be admitted to the POU with conditions outside of those in which guidelines were originally developed. These cases were reviewed and analysed by unit leadership at regular monthly meetings, with the aim of creating new admission guidelines to increase the census of the POU.

\section{Patients requiring continuous nebulised albuterol}

Current clinical practice allowed for the transfer of patients to the paediatric intensive care unit (PICU) who were in respiratory distress requiring continuous nebulised albuterol. A preliminary review of transferred patients revealed that several were discharged home within 48 hours. Hence, the aim of this cycle was to reduce the rate of PICU transfers for asthma exacerbations by $25 \%$ in a 4-month period by admitting these children to the POU and providing 6 hours of continuous albuterol with close clinical monitoring prior to a decision to transfer to the PICU. Disposition, total LOS including POU, PICU, and inpatient portions of the admission, and any adverse events were noted and reviewed.

\section{System admissions}

Beginning in late 2017, the POU began accepting children for admission from other EDs within the healthcare system. Initially, the admission destination was determined by the outside admitting ED physician. Due to a gap in knowledge regarding POU admission capabilities, this resulted in a high missed POU admission rate, defined as the proportion of children being transferred to the inpatient unit who met POU admission criteria over the total number of children transferred to the POU and inpatient unit. In order to appropriately assign bed resources within the hospital system and avoid overcrowding in the children's hospital, an intervention was initiated where the POU and inpatient hospitalists were conference called into all paediatric admission requests from the health system, with the aim of reducing the missed POU admission rate by $10 \%$ over a 4 -month period.

\section{Study of the interventions}

Within the POU, data metrics chosen to measure quality and impact of the service included patient volume, LOS, admission diagnoses, conversion rate, 72 hours' unexpected return to ED or hospitalisation within 72 hours following discharge and patient satisfaction measured by Press-Ganey surveys. These metrics were collected on a monthly basis as a means of obtaining baseline measures as well as to gauge the impact of the above interventions. The diagnosis and interventions required for patients with LOS less than 48 hours for transferred and direct PED to inpatient floor times were evaluated to help expand admission guidelines and safely expand interventions given in the POU. Data for analysis were collected from January 2017 through December 2018, and reported as frequencies with proportions and means as appropriate; activities were approved by the institutional review board.

\section{Patient and public involvement}

The research question and outcome measures were derived from traditional patient throughput, resource utilisation and patient-related outcome reporting. Data from patient hospitalisations such as LOS, patient satisfaction and dispositions were collected as outcome measures. At the time of consent to participate, patients and their caregivers were provided contact information for the principal investigator and programme should they wish to review study results in the future.

\section{RESULTS}

\section{PED census and patient dispositions}

The combined PED and POU opened in January 2017. In the ensuing 2 years, the PED had a census of 11745 
Table 1 Admission destination from paediatric emergency department

\begin{tabular}{lrrrrrr}
\hline & \multicolumn{2}{c}{$\mathbf{2 0 1 7}$} & & & $\mathbf{2 0 1 8}$ & \\
\cline { 2 - 3 } \cline { 6 - 6 } & $\mathbf{n}$ & $\mathbf{\%}$ & & $\mathbf{n}$ & \% \\
\hline Paediatric observation unit & 299 & 56.5 & & 478 & 69.7 \\
System children's hospital & 132 & 25.0 & 111 & 16.2 \\
Adult inpatient units & 49 & 9.2 & 52 & 7.6 \\
Outside hospitals & 49 & 9.3 & 45 & 6.5 \\
Total admissions & 529 & 100 & 686 & 100 \\
\hline
\end{tabular}

and 12293 patients, respectively, in 2017 and 2018. Five hundred and twenty-nine $(4.5 \%)$ required admission in 2017 and $686(5.6 \%)$ in 2018. Of those requiring admission, $56.5 \%$ and $69.7 \%$ were admitted to the POU in 2017 and 2018, respectively. Other admission destinations are listed by year in table 1 .

\section{POU metrics and patient outcomes}

The average LOS in the POU was 25.7hours in 2017 and 26.5 hours in 2018. Of the 777 admissions to the POU over the 2-year period, 34 patients $(4.4 \%)$ had a LOS less than 8 hours and 45 patients $(5.8 \%)$ had a LOS greater than 48 hours. A majority of the patients with LOS $<8$ hours were those with respiratory illnesses who failed initial therapy and required increased support and thus transferred to the PICU. Over the 2-year period, a total of 1612 hospital inpatient days were diverted from the referring children's hospital.

There were 119 (15.3\%) conversions to inpatient and intensive care unit admission. Thirty $(25.2 \%)$ were transferred to the PICU, 27 (22.6\%) were transferred to inpatient psychiatric units, $47(39.4 \%)$ to the general inpatient unit after exceeding the time limit in observation and 15 $(12.6 \%)$ were transferred for surgical intervention. Ten patients had repeat visits to the PED and four patients were subsequently admitted to inpatient care within 72 hours of discharge from the observation unit. Of the return visits, six were for complaints unrelated to the initial admission. Results reported by year are displayed in table 2.

Of the 777 children admitted, $318(41.0 \%)$ were for respiratory illnesses, $98(12.7 \%)$ for dehydration, 77 $(9.9 \%)$ for psychiatric conditions, $62(8.0 \%)$ for skin and soft tissue infections and $27(3.4 \%)$ for pyelonephritis (table 3).

\section{Patient satisfaction}

Prior to the opening of the observation unit, the percentile rank for peer groups on the 'Likelihood to Recommend' question on the Press Ganey survey was 36th percentile for the PED. One year following the opening of the combined PED-POU, the percentile rank increased to the 92nd percentile for the PED-POU for the same question. Response rates averaged 1.2\%.

\begin{tabular}{|c|c|c|c|c|}
\hline & \multicolumn{2}{|l|}{2017} & \multicolumn{2}{|l|}{2018} \\
\hline & Patients & $\%$ & Patients & $\%$ \\
\hline Total POU admissions & 299 & 100 & 478 & 100 \\
\hline Average LOS (hours) & 25.7 & & 26.5 & \\
\hline \multicolumn{5}{|l|}{$\begin{array}{l}\text { LOS <8 hours or } \\
>48 \text { hours }\end{array}$} \\
\hline LOS $<8$ hours & 11 & 3.6 & 23 & 4.8 \\
\hline LOS $>48$ hours & 13 & 4.4 & 32 & 6.7 \\
\hline Patient hospital days & 596 & & 1016 & \\
\hline $\begin{array}{l}\text { Conversions to } \\
\text { hospitalisation }\end{array}$ & 56 & 18.7 & 63 & 13.1 \\
\hline \multicolumn{5}{|l|}{ Unanticipated revisits } \\
\hline PED visit & 7 & 2.3 & 3 & 0.6 \\
\hline Admission & 2 & 0.7 & 2 & 0.4 \\
\hline
\end{tabular}

LOS, length of stay; PED, paediatric emergency department; POU, paediatric observation unit.

\section{Quality improvement cycles}

Adjustments to admission guidelines

An initial review of LOS for various transferred diagnoses revealed that a majority of patients with psychiatric complaints, neonatal jaundice and febrile infants remained hospitalised for less than 48 hours. Collaboration with colleagues in child and adolescent psychiatry allowed for the development of a clinical guideline where children requiring psychiatric observation were admitted to the POU and prioritised for evaluation. Other guidelines were developed to expand the admission criteria for diagnoses such as hyperbilirubinaemia and febrile infants less than 2 months old. Combined, these three diagnoses resulted in 34 additional admissions, increasing the annual census of the POU by $11.3 \%$ by the end of 2017 and accounted for $18.4 \%$ of the admissions in 2018. The number of conditions for which admission guidelines exist increased from 8 to 24 over the first 2 years after the opening of the POU.

\begin{tabular}{|c|c|c|}
\hline Diagnosis & Patients & $\%$ \\
\hline Respiratory & 318 & 41.0 \\
\hline Dehydration & 98 & 12.7 \\
\hline Psychiatric & 77 & 9.9 \\
\hline Skin/soft tissue infection & 62 & 8.0 \\
\hline Abdominal pain & 40 & 5.1 \\
\hline UTI & 27 & 3.4 \\
\hline Anaphylaxis & 31 & 4.0 \\
\hline Toxic ingestion & 14 & 1.8 \\
\hline Miscellaneous & 110 & 14.1 \\
\hline Total & 777 & 100 \\
\hline
\end{tabular}

UTI, urinary tract infection. 


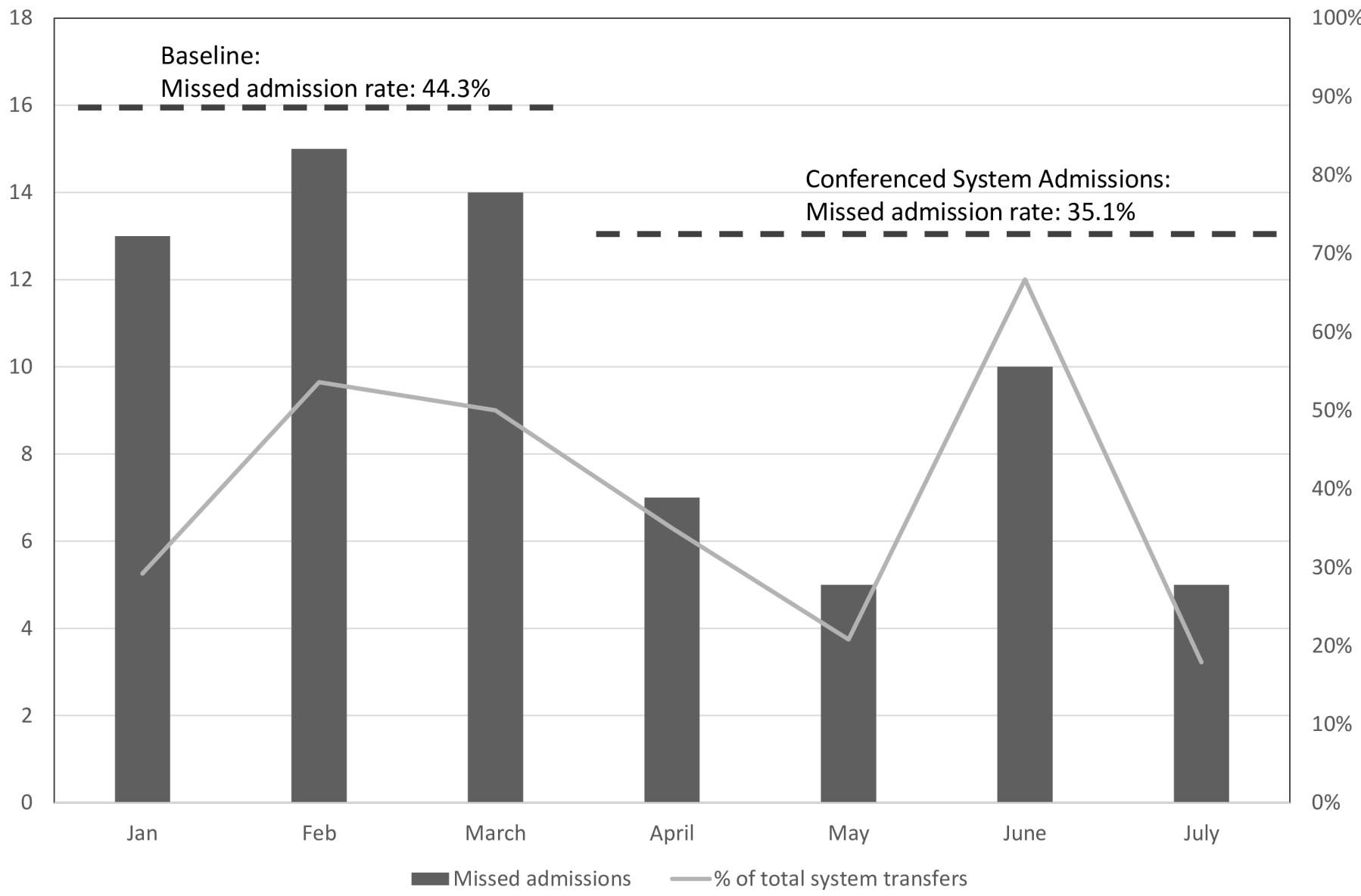

Figure 1 Missed eligible admissions from system hospitals. Percentage of paediatric admissions from four system emergency departments (solid line) and number of patients (bars) meeting paediatric observation unit (POU) eligibility criteria who were admitted to the inpatient unit. Dashed line indicates periods before and during implementation of a conference call system allowing comanagement and determination of appropriate bed assignment.

\section{Patients requiring continuous nebulised albuterol}

From August 2017 to December 2017, nine children with respiratory distress required continuous albuterol in the POU. Following admission to the POU and after receiving 6 hours of continuous nebulised albuterol, four were subsequently transferred to the PICU; all four patients remained hospitalised for greater than 48 hours. Of the remaining five, all were discharged from the POU within 48 hours and none returned to the PED or were admitted within 72 hours. This intervention reduced the rate of transfers to the PICU by $55.6 \%$ within the 4 -month period of the intervention.

\section{System admissions}

In the 3 months prior to the intervention, $44.3 \%$ of children meeting POU admission criteria were transferred to the inpatient unit at the system children's hospital. In the 4 months following the implementation of the conference call system, that rate decreased by $9.2 \%$ to $35.1 \%$ (figure 1); this approached the $10 \%$ reduction goal set for this quality improvement cycle. Over the remainder of the year, 102 patients were admitted from system hospitals, representing $21.3 \%$ of the POU census.

Over the 2-year period of the study, there was an increasing trend in the number of monthly admissions over time while maintaining a stable LOS and conversion rate within goal thresholds. The aforementioned quality improvement interventions contributed to increasing the mean monthly census from a baseline of 18.1 patients per month to 41.3 per month over a 2-year period (figure 2).

\section{DISCUSSION}

Impact

The implementation of the combined PED-POU has been beneficial at our institution. The combined design had the benefits of concentrating paediatric specialty care within the hospital and maximised the work effort of specifically trained staff to improve patient care and safety. The POU demonstrated an increasing patient census while maintaining goals for LOS and conversion rates, and reduced the inpatient burden on the referring children's hospital while improving patient satisfaction.

We did not meet the initial goal of a $15 \%$ conversion rate in the first year. This was primarily driven by changes in hospital policies in August 2017 allowing for these patients to be accepted to the POU. These young adults had a higher rate of conversion, but also could be admitted to adult beds within our hospital, avoiding the outside transfer that younger children requiring 


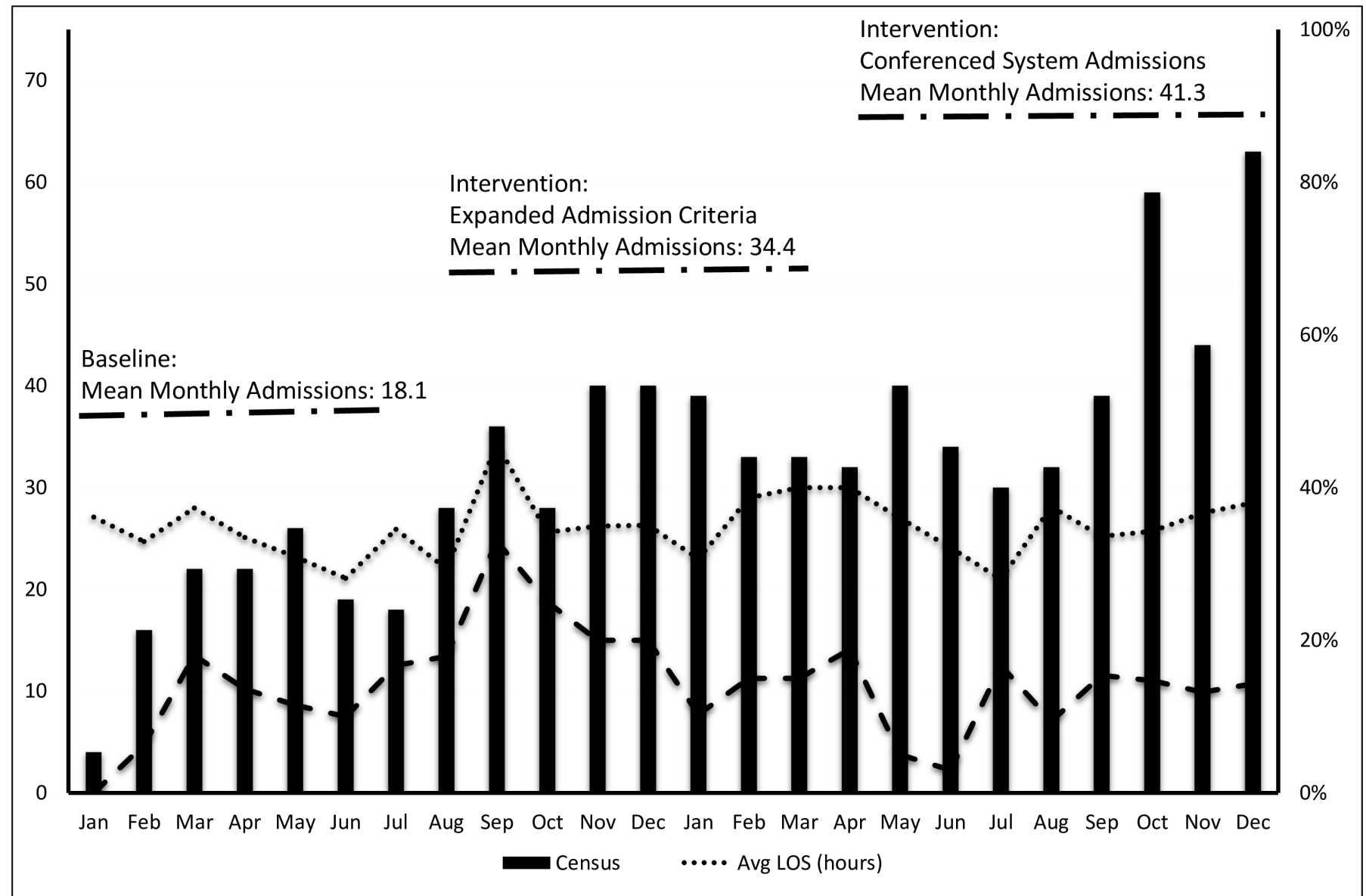

Figure 2 Paediatric observation unit census, length of stay and conversions from January 2017 to December 2018 . Number of admissions (bar), average length of stay in hours (dotted line) and percentage of patients converted to inpatient hospitalisation (dashed line). Dashed and dotted lines represent individual quality improvement periods and the corresponding mean monthly admissions in each period. LOS, length of stay.

conversion would require. We were able to meet the benchmark conversion rate in 2018. Subsequent expansion in the scope of services provided by the POU through quality improvement interventions such as changes and additions to existing clinical guidelines and acceptance of eligible transfers from other hospitals have made the POU integral to patient care within the hospital and healthcare system.

Continuous quality improvement of tracking admissions from the PED and conversions from the POU to the referring children's hospital was found to be a successful method of adjusting admission and management guidelines to optimise resources. For example, as the majority of paediatric admissions for our institution were for respiratory conditions, the focus of initial efforts was to optimise selection among these patients. Significant reductions in the transfer of children to the PICU with respiratory distress requiring continuous albuterol demonstrated in an improvement cycle drove the adjustment of guidelines to allow for the admission of these patients to the POU.

The opportunity to admit patients to the POU with conditions outside of current guidelines and close scrutiny of the cases and subsequent patient outcomes provided the opportunity to expand acceptable diagnoses. Work is ongoing for the provision of on-site consultation by paediatric subspecialties that will allow for the acceptance of diagnoses such as diabetic hyperglycaemia and reduced intussusception. Incorporating perioperative services for paediatric ambulatory procedures into the scope of services of the POU can ensure a steady census while further leveraging the paediatric subspecialty care that can be provided by the POU staff.

Stakeholders in the emergency medicine and paediatrics continue collaborative efforts to optimise the impact of the PED-POU on resource utilisation and improve family-focused care throughout the health system. Conferenced admission calls improved the efficiency of paediatric admissions throughout the health system and increased the capture of eligible POU patients. Ongoing quality assurance ensures proper patient selection to prevent unnecessary conversions requiring 'double transfers'-or initial admission to the POU followed by conversion to inpatient units. Utilisation of telemedicine resources has allowed for the collection of additional clinical information to help best determine the proper disposition of a patient, as well as provide a means for a 'warm handoff' for providers and families. 


\section{Lessons and limitations}

Important lessons were learnt in our experience with implementing a combined PED-POU. Developing a staffing model that provided service to children in adjacent units with differing care goals proved to be a challenge. Providers initially found difficulty in shifting between the acute care demands of the PED and the ongoing management, advancement of care and disposition planning in the POU. With increased experience, better delineation of patient care responsibilities and additional cross-training, providers were able to better distribute their efforts between the two units.

Our project did present limitations. A cost analysis was not included in this report, which would factor the cost to build and maintain the combined unit offset with the benefit of more efficient throughput of patients in the PED. Such a cost analysis would also compare the costs of inpatient versus observation care, and calculate potential gains in the health system by providing more available beds in the children's hospital for children with more complex conditions. The impact and extent of potential cost benefit to families, insurance providers and the hospital system was beyond the scope of this report.

There are also limitations that could have impacted our analysis. Unexpected return to care was determined by patient callbacks 72 hours after discharge. For those not answering those calls and lost to follow-up, we could not confirm if they sought care at other centres outside of our healthcare system. Though consistent with other similar survey response rates, patient satisfaction ratings were obtained from a limited number of respondents, and may not accurately represent the patient experience of families in the PED.

\section{CONCLUSION}

The implementation of a combined PED and POU at our institution allowed for the ability to provide paediatric specialty services to children and families presenting to the hospital. Evidence-based and data-driven guidelines provide the framework to care for conditions that are ideally suitable for the combined unit. A majority of patients requiring admission from the PED were able to be successfully managed in the POU, which has reduced the burden on inpatient beds at the referring children's hospital. As additional paediatric services are provided, more rapid means of transport devised and the unit staff becomes more practised with high-turnover patients, additional diagnoses will be accepted for admission to the POU. To our knowledge, this is the first report detailing the development of a combined PED and POU in a community hospital without paediatric inpatient services.

Contributors CAEL was involved in the planning of the programme and in study design, data collection, analysis and manuscript development. J0 was involved in study design, data collection and analysis, manuscript development and submission. EE was involved in study design and implementation, data analysis and manuscript development. CC was involved in the planning of the programme and manuscript development. YC and BB were involved in the planning of the programme and in study design, data analysis and manuscript development.

Funding The authors have not declared a specific grant for this research from any funding agency in the public, commercial or not-for-profit sectors.

Competing interests None declared.

Patient consent for publication Not required.

Provenance and peer review Not commissioned; externally peer reviewed.

Data availability statement Data are available upon request.

Open access This is an open access article distributed in accordance with the Creative Commons Attribution Non Commercial (CC BY-NC 4.0) license, which permits others to distribute, remix, adapt, build upon this work non-commercially, and license their derivative works on different terms, provided the original work is properly cited, appropriate credit is given, any changes made indicated, and the use is non-commercial. See: http://creativecommons.org/licenses/by-nc/4.0/.

ORCID iD

Czer Anthoney Enriquez Lim http://orcid.org/0000-0001-8522-502X

\section{REFERENCES}

1 Conners GP, Melzer SM, Betts JM, et al. Pediatric observation units. Pediatrics 2012;130:172-9.

2 Macy ML, Kim CS, Sasson C, et al. Pediatric observation units in the United States: a systematic review. J Hosp Med 2010;5:172-82.

3 Dudas RA, Monroe D, McColligan M. Community pediatric hospitalists providing care in the emergency department: an analysis of physician productivity and financial performance. Pediatr Emerg Care 2011;27:1099-103.

4 Freed GL, Brzoznowski K, Neighbors K, et al. Characteristics of the pediatric hospitalist workforce: its roles and work environment. Pediatrics 2007;120:33-9.

5 Gaynor M, Anderson GF, demand U. Uncertain demand, the structure of hospital costs, and the cost of empty hospital beds. $J$ Health Econ 1995;14:291-317.

6 Aragona E, Rauch DA. Pediatrics. Ongoing Trends in Pediatric Hospitalizations [Internet], 2017. Available: http://pediatrics. aappublications.org/content/140/1_MeetingAbstract/33

7 Levett I, Berry K, Wacogne I. Review of a paediatric emergency department observation unit. Emergency Medicine Journal 2006;23:612-3.

8 Leyenaar JK, Ralston SL, Shieh M-S, et al. Epidemiology of pediatric hospitalizations at general hospitals and freestanding children's hospitals in the United States. J Hosp Med 2016;11:743-9.

9 Macy ML, Stanley RM, Sasson C, et al. High turnover stays for pediatric asthma in the United States: analysis of the 2006 kids' inpatient database. Med Care 2010;48:827-33.

10 Zebrack M, Kadish H, Nelson D. The pediatric hybrid observation unit: an analysis of 6477 consecutive patient encounters. Pediatrics 2005;115:e535-42.

11 Goodman DC, Fisher ES, Gittelsohn A, et al. Why are children hospitalized? the role of non-clinical factors in pediatric hospitalizations. Pediatrics 1994;93:896-902.

12 Khare M, Goudie A, Rauch DA. National pediatric bed occupancy. pediatrics, 2018141 (1 MeetingAbstract) 420. Available: http:// pediatrics.aappublications.org/content/141/1_MeetingAbstract/420? utm_source=TrendMD\&utm_medium=TrendMD\&utm_campaign= Pediatrics_TrendMD_0

$13 \mathrm{Li} \mathrm{J}$, Monuteaux MC, Bachur RG. Interfacility transfers of noncritically ill children to academic pediatric emergency departments. Pediatrics 2012;130:83-92.

14 Athey J, Dean JM, Ball J, et al. Ability of hospitals to care for pediatric emergency patients. Pediatr Emerg Care 2001;17:170-4.

15 Middleton KR, Burt CW. Availability of pediatric services and equipment in emergency departments: United States, 2002-03. Hyattsville, MD. Natl Health Stat Report 2006;367.

16 Lee K-soo, Chun K-hong, Lee J-soo, et al. Reforming the hospital service structure to improve efficiency: urban Hospital specialization. Health Policy 2008;87:41-9.

17 Schneider JE, Miller TR, Ohsfeldt RL, et al. The economics of specialty hospitals. Med Care Res Rev 2008;65:531-53.

18 Porter ME, Teisberg EO. Redefining health care: creating value-based competition on results. Boston: Harvard Business School Press, 2006.

19 Chang R-KR, Klitzner TS. Can regionalization decrease the number of deaths for children who undergo cardiac surgery? A theoretical analysis. Pediatrics 2002;109:173-81. 
20 Salazar JH, Goldstein SD, Yang J, et al. Regionalization of pediatric surgery: trends already Underway. Ann Surg 2016;263:1062-6.

21 Morris ZS, Boyle A, Beniuk K, et al. Emergency department crowding: towards an agenda for evidence-based intervention: Figure 1. Emerg Med J 2012;29:460-6.

22 Freedman SB, Thakkar VA. Easing the strain on a pediatric tertiary care center: use of a redistribution system. Arch Pediatr Adolesc Med 2007;161:870-6.

23 Hillier DF, Parry GJ, Shannon MW, et al. The effect of hospital bed occupancy on throughput in the pediatric emergency department. Ann Emerg Med 2009;53:767-76.

24 Fieldston ES, Hall M, Sills MR, et al. Children's hospitals do not acutely respond to high occupancy. Pediatrics 2010;125:974-81.

25 Chan TC, Killeen JP, Castillo E, et al. 13. Ann Emerg Med 2006;48:5-6.

26 Derlet RW, Richards JR. Overcrowding in the nation's emergency departments: complex causes and disturbing effects. Ann Emerg Med 2000;35:63-8.

27 Alkhoury F, Burnweit C, Malvezzi L, et al. A prospective study of safety and satisfaction with same-day discharge after laparoscopic appendectomy for acute appendicitis. J Pediatr Surg 2012;47:313-6.

28 Flores G, Abreu M, Chaisson CE, et al. Keeping children out of hospitals: parents' and physicians' perspectives on how pediatric hospitalizations for ambulatory Care-Sensitive conditions can be avoided. Pediatrics 2003;112:1021-30.

29 Lieu TA, Quesenberry CP, Capra AM, et al. Outpatient management practices associated with reduced risk of pediatric asthma hospitalization and emergency department visits. Pediatrics 1997;100:334-41.

30 Macy ML, Stanley RM, Lozon MM, et al. Trends in high-turnover stays among children hospitalized in the United States, 1993-2003. Pediatrics 2009;123:996-1002.

31 Cullen KA, Hall MJ, Golosinskiy A. Ambulatory surgery in the United States, 2006. Natl Health Stat Report. Hyattsville, Md: U.S. Dept. of Health and Human Services, Centers for Disease Control and Prevention, 2009 Report No. 11.

32 Tagge EP, Hebra A, Overdyk F, et al. One-Stop surgery: evolving approach to pediatric outpatient surgery. J Pediatr Surg 1999;34:129-32.
33 Greenberg RA, Dudley NC, Rittichier KK. A reduction in hospitalization, length of stay, and hospital charges for croup with the institution of a pediatric observation unit. Am J Emerg Med 2006;24:818-21.

34 Kattan M, Stearns SC, Crain EF, et al. Cost-Effectiveness of a homebased environmental intervention for inner-city children with asthma. J Allergy Clin Immunol 2005;116:1058-63.

35 Marks MK, Lovejoy FH, Rutherford PA, et al. Impact of a short stay unit on asthma patients admitted to a tertiary pediatric hospital. Qual Manag Health Care 1997;6:14-22.

36 Sandweiss DR, Mundorff MB, Hill T, et al. Decreasing Hospital length of stay for bronchiolitis by using an observation unit and home oxygen therapy. JAMA Pediatr 2013;167:422-8.

37 Yen K, Gorelick MH. Strategies to improve flow in the pediatric emergency department. Pediatr Emerg Care 2007;23:745-9.

38 lannone P, Lenzi T. Effectiveness of a multipurpose observation unit: before and after study. Emerg Med J 2009;26:407-14.

39 Willis R, Crowley S, Hutton A. Paediatric extended emergency care (PEEC): establishing and evaluating a paediatric short-stay ward: a pilot study. Neonatal Paediatric Child Health Nurs 2011;14:3-8.

40 Wiley JF, Friday JH, Nowakowski T, et al. Observation units: the role of an outpatient extended treatment site in pediatric care. Pediatr Emerg Care 1998;14:444-7.

41 Scribano PV, Wiley JF, Platt K. Use of an observation unit by pediatric emergency department for common pediatric illnesses. Pediatr Emerg Care 2001;17:321-3.

42 Gouin S, Patel H. Utilization analysis of an observation unit for children with asthma. Pediatr Emerg Care 1999;15:79-83.

43 McConnochie KM, Russo MJ, McBride JT, et al. Socioeconomic variation in asthma hospitalization: excess utilization or greater need? Pediatrics 1999;103:e75-8.

44 Listernick R, Zieserl E, Davis T. Outpatient oral rehydration in the United States. Arch Pediatr Adolesc Med 1986;140:211-5.

45 Willert C, Davis AT, Herman JJ, et al. Short-Term holding room treatment of asthmatic children. J Pediatr 1985;106:707-11.

46 Macy ML, Hall M, Shah SS, et al. Pediatric observation status: are we overlooking a growing population in children's hospitals? J. Hosp. Med. 2012;7:530-6. 